\title{
PENGARUH STRATEGI PENGEMBANGAN SDM TERHADAP KINERJA KARYAWAN
}

\author{
Rita Widjaja \\ Program Studi Magister Manajemen Universitas Tarumanagara \\ filbertkenneth@yahoo.com \\ Eddy Supriyatna MZ \\ Program Studi Magister Manajemen Universitas Tarumanagara
}

Masuk : 07-10-2019, revisi : 05-11-2019 diterima untuk diterbitkan : 05-11-2019

\begin{abstract}
This research aims to determine the effect of training, work dicipline and organization communication toward employee performance. The sample used in the study amounted to 158 employees. The research method uses multiple linear regression analysis with the help of managing data using SPSS version 22 software. The results of this study indicate that training, organization communication partially have a significant effect on the employee performance, and work dicipline partially haven't a significant effect on the employee performances. And training, work dicipline, organization communication a simultaneously have a significant effect on the employees Performances.
\end{abstract}

Keywords : Training, Work Discipline, Organization Communication and Employees Performance.

Abstrak : Penelitian ini bertujuan untuk mengetahui pengaruh pelatihan, disiplin kerja dan komunikasi organisasi terhadap kinerja karyawan. Sampel yang digunakan dalam penelitian ini berjumlah 158 karyawan. Metode penelitian menggunakan analisis regresi linier berganda dan pengelolaan data menggunakan perangkat lunak SPSS versi 22. Hasil penelitian ini menunjukkan bahwa pelatihan, komunikasi organisasi secara parsial berpengaruh signifikan terhadap kinerja karyawan, namun disiplin kerja secara parsial tidak berpengaruh signifikan terhadap kinerja karyawan. Secara simultan pelatihan, disiplin kerja, komunikasi organisasi memiliki pengaruh yang signifikan terhadap Kinerja karyawan.

Kata kunci : Pelatihan, Disiplin Kerja, Komunikasi Organisasi dan Kinerja karyawan.

\section{PENDAHULUAN}

Sumber daya manusia yang memiliki keunggulan kompetitif merupakan salah satu ciri sumber daya manusia yang berkinerja baik. Sumber daya manusia adalah faktor sentral dalam satu organisasi karena sumber daya inilah yang akan mencapai visi dan dalam pelaksanaannya misi tersebut dikelola oleh manusia. (Ike Kusdyah, 2008:22).

PT Asuransi Mega Pratama memiliki beberapa permasalahan yang berkaitan kinerja karyawan, terlihat dengan terjadinya penurunan penjualan pada 4 tahun terakhir tidak tercapai sesuai target. Banyak hal yang mempengaruhi kinerja suatu perusahaan. Hal yang paling erat berkaitan dengan kemampuan SDM adalah melalui pelatihan, disiplin dalam bekerja dan komunikasi dalam organisasi. Untuk itu penulis tertarik meneliti Pengaruh Strategi Pengembangan SDM Terhadap Kinerja Karyawan.

\section{PERUMUSAN HIPOTESIS}

H1 : Terdapat pengaruh Pelatihan terhadap Kinerja Karyawan

H2 : Terdapat pengaruh Disiplin Kerja terhadap Kinerja Karyawan 
H3 : Terdapat pengaruh Komunikasi Organisasi terhadap Kinerja Karyawan

H4 : Terdapat pengaruh secara simultan antara Pelatihan, Disiplin Kerja, dan Komunikasi Organisasi Terhadap Kinerja Karyawan

\section{METODE PENELITIAN}

\section{Waktu, Sumber Data, Populasi, Sampel dan Teknik Pengambilan Sampel}

Penelitian ini merupakan penelitian kausal. Data yang digunakan adalah data Primer yang dikumpulkan dari kuesioner terhadap 158 karyawan PT. AMP dan data sekunder yang diambil dari studi pustaka dan informasi lain yang berhubungan dengan masalah yang sedang diteliti. Waktu penelitian pada bulan 1 Februari 2019 - 31 Juli 2019, yang tersebar di 14 kota. Teknik pengambilan sampel menggunakan sampel jenuh adalah sensus.

\section{Operasionalisasi Variabel}

Operasionalisasi variabel pada penelitian ini dengan dua jenis variabel yaitu Variabel Bebas (X) Variabel independent (mempengaruhi) variabel yang lain yaitu : X1 : Pelatihan, X2 : Disiplin Kerja dan X3 : Komunikasi Organisasi. Sedangkan Variabel Terikat (dipengaruhi) adalah Y : Kinerja Karyawan.

\section{HASIL UJI INSTRUMEN DAN HASIL UJI ASUMSI KLASIK Uji Validitas \& Realibilitas}

Hasil uji validitas ternyata semua item pertanyaan valid karena rhitung > rtabel . Tabel kritis pengujian validitas dengan $n=30$ diperoleh nilai $r$ tabel sebesar 0.361. Dan hasil uji reliabilitas semua item variabel dinyatakan reliabel karena nilai Cronbach Alpha menunjukan $>0,600$, maka semua variabel dikatakan reliabel.

\section{Tabel 1.1}

Hasil Uji Reliabilitas

\begin{tabular}{|l|c|c|c|}
\hline \multicolumn{1}{|c|}{ Variabel } & $\begin{array}{c}\text { Cronbach's } \\
\text { Alpha }\end{array}$ & Syarat & Keterangan \\
\hline Pelatihan & 0.950 & $>0,600$ & Reliabel \\
\hline Disiplin & 0.887 & $>0,600$ & Reliabel \\
\hline $\begin{array}{l}\text { Komunikasi } \\
\text { Organisasi }\end{array}$ & 0.942 & $>0,600$ & Reliabel \\
\hline Kinerja & 0.827 & $>0,600$ & Reliabel \\
\hline
\end{tabular}

Sumber : Data primer yang diolah (2019)

\section{Uji Normalitas}

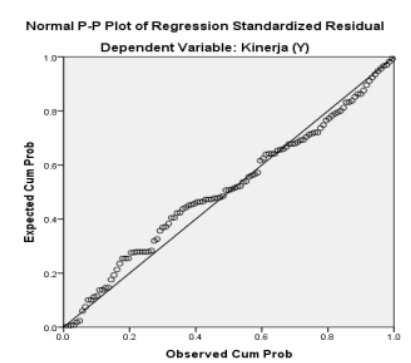

Gbr 1.1. Grafik Normalitas
Berdasarkan gambar 1.1, dapat dilihat bahwa hubungan Pelatihan, Disiplin Kerja dan Komunikasi Organisasi terhadap Kinerja karyawan menunjukkan pola distribusi normal dimana data menyebar disekitar garis diagonal mengikuti garis diagonal. Maka nilai residual tersebut terdistribusi normal. 


\section{Uji Multikolinearitas}

Tabel 1.2

Hasil Uji Multikoleniaritas

\begin{tabular}{|l|c|c|}
\hline Variabel & Tolerance & \multicolumn{1}{l|}{ VIF } \\
\hline Plth (X1) & .512 & 1.952 \\
\hline Dspl (X2) & .865 & 1.156 \\
\hline Komg (X3) & .516 & 1.938 \\
\hline
\end{tabular}

Sumber : Data Diolah Penulis (2019)

Nilai VIF variabel X1 1.952 , variabel X2 1.156 dan variabel X3 1.938 dan nilai VIF ketiga variabel bebas $<10$ serta nilai tolerance dibawah 1 yang artinya tidak terdapat hubungan yang linier antara variabel bebas (independen) satu dengan variabel bebas (independen) yang lainnya.

\section{Uji Heterokedastisitas}

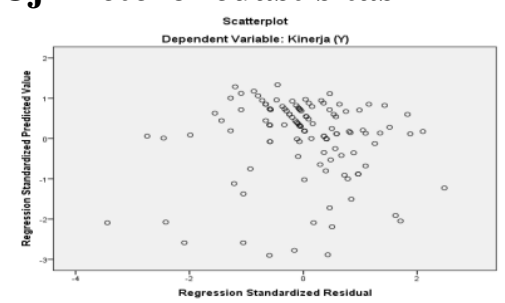

Gbr. 1.2 Hasil uji heteroskedastisitas
Sebaran titik menyebar diatas dan bawah garis nol serta tidak membentuk pola tertentu, sehingga dapat dinyatakan bahwa data yang diperoleh berasal dari varian yang sama (tidak terjadi gejala heteroskedastisitas).

\section{Uji Autokorelasi}

Hasil analisis autokorelasi menunjukkan bahwa nilai Durbin-Watson sebesar 1.316, nilai tersebut mendekati angka 2. dengan demikian dapat disimpulkan bahwa tidak terjadi autokorelasi di antara data pengamatan.

Tabel 1.3

Hasil Uji Autokorelasi

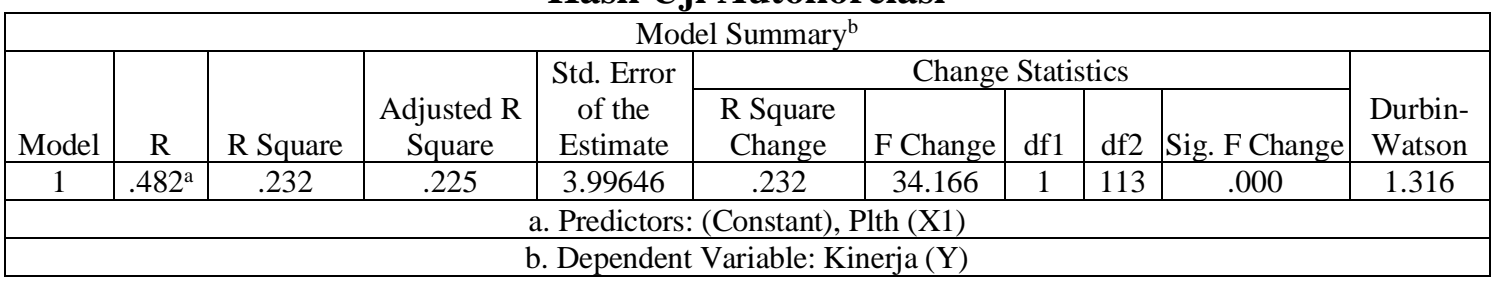

Sumber : Data Primer Yang Diolah (2019)

\section{UJI HIPOTESIS}

\section{Uji Regresi Linier Berganda}

Tabel 1.4

Hasil Analisa Regresi

\begin{tabular}{|c|c|c|c|c|c|c|}
\hline & \multirow[t]{2}{*}{ Model } & \multicolumn{2}{|c|}{ Unstandardized Coefficients } & \multirow{2}{*}{$\begin{array}{c}\begin{array}{c}\text { Standardized } \\
\text { Coefficients }\end{array} \\
\text { Beta } \\
\end{array}$} & \multirow[t]{2}{*}{$\mathrm{t}$} & \multirow[t]{2}{*}{ Sig. } \\
\hline & & B & Std. Error & & & \\
\hline \multirow{4}{*}{1} & (Constant) & 48.441 & 4.920 & & 9.846 & .000 \\
\hline & Plth (X1) & .136 & .064 & .238 & 2.140 & .035 \\
\hline & Dspl (X2) & .036 & .077 & .040 & .468 & .641 \\
\hline & Komg (X3) & .197 & .066 & .334 & 3.010 & .003 \\
\hline & \multicolumn{6}{|c|}{ a. Dependent Variable: KINERJA } \\
\hline
\end{tabular}

Hasil perolehan angka diatas dikonversikan ke dalam persamaan regresi linier berganda adalah sebagai berikut: Y=48.441+0,136X_1+0.036 X2+0,197X_3 


\section{Uji Koefisien Determinasi}

Tabel 1.5

Hasil Koefesien Determinasi

\begin{tabular}{|ccccc|}
\hline \multicolumn{4}{|c|}{ Model Summary $^{\mathrm{b}}$} \\
\hline Model & $\mathrm{R}$ & $\mathrm{R}$ Square & Adjusted R Square & Std. Error of the Estimate \\
\hline 1 & $.543^{\mathrm{a}}$ & .295 & .276 & 3.86390 \\
\hline a. Predictors: (Constant), Pelatihan, Disiplin, Komunikasi Organisasi, \\
\hline b. Dependent Variable: KINERJA \\
\hline
\end{tabular}

Sumber : Data Primer Yang Diolah (2019)

Hal ini berarti sumbangan variabel independen dalam hal pelatihan, disiplin kerja dan komunikasi organisasi sebesar 27,6 \% sedangkan sisanya 72,4 \% dijelaskan oleh faktor-faktor lain. Standar Error of the Estimate (SEE) adalah sebesar 3.863. Semakin kecil nilai SEE maka akan membuat model regresi semakin tepat dalam memprediksi variabel dependen. Nilai $\mathrm{R}$ sebesar 0.543 dan nilai Adjusted R Square sebesar 0,295. Semakin besar nilai Adjusted R Square mendekati angka 1 (satu), maka variabel independen (Pelatihan, Disiplin kerja, Komunikasi Organisasi) berpengaruh semakin kuat terhadap variabel dependent (Kinerja)

\section{Uji F (Uji Simultan)}

Tabel 1.6

Hasil Uji F

\begin{tabular}{|c|c|c|c|c|c|c|}
\hline \multicolumn{7}{|c|}{ ANOVA $^{\mathrm{a}}$} \\
\hline Model & & Sum of Squares & $\mathrm{df}$ & Mean Square & $\mathrm{F}$ & Sig. \\
\hline 1 & Regression & 693.288 & 3 & 231.096 & 15.479 & $.000^{\mathrm{b}}$ \\
\hline & Residual & 1657.199 & 111 & 14.930 & & \\
\hline & Total & 2350.487 & 114 & & & \\
\hline \multicolumn{7}{|c|}{ a. Dependent Variable: Kinerja (Y) } \\
\hline b. Pred & tors: (Const: & Komg (X3), Dspl & , Plth & & & \\
\hline
\end{tabular}

Berdasarkan dari tabel diatas diketahui bahwa $\mathrm{F}$ hitung $>\mathrm{F}$ tabel $(15,479>2,70)$. Hal ini (X1), (X2), (X3) secara bersama-sama (simultan) terhadap (Y). Hipotesis yang diajukan artinya: Ho ditolak dan Ha di terima.

\section{Uji t (Uji Parsial)}

Tabel 1.7 Hasil Uji t

\begin{tabular}{|c|c|c|c|c|c|c|}
\hline & \multirow[t]{2}{*}{ Model } & \multicolumn{2}{|c|}{ Unstandardized Coefficients } & $\begin{array}{c}\text { Standardized } \\
\text { Coefficients }\end{array}$ & \multirow[t]{2}{*}{$\mathrm{t}$} & \multirow[t]{2}{*}{ Sig. } \\
\hline & & $\mathrm{B}$ & Std. Error & Beta & & \\
\hline \multirow{4}{*}{1} & (Constant) & 48.441 & 4.920 & & 9.846 & .000 \\
\hline & Plth (X1) & .136 & .064 & .238 & 2.140 & .035 \\
\hline & Dspl (X2) & .036 & .077 & .040 & .468 & .641 \\
\hline & Komg (X3) & .197 & .066 & .334 & 3.010 & .003 \\
\hline & \multicolumn{6}{|c|}{ a. Dependent Variable: KINERJA } \\
\hline
\end{tabular}

- $t_{\text {hitung }}>\mathrm{t}_{\text {tabel }}(2,140>1,658)$ maka $\mathrm{H}_{\mathrm{o}}$ ditolak yang berarti terdapat pengaruh antara variabel pelatihan terhadap kinerja karyawan. Dilihat dari signifikansi $0,000<0,035$ sehingga $\mathrm{H}_{\mathrm{o}}$ ditolak. 
- $\mathrm{t}_{\text {hitung }}<\mathrm{t}_{\text {tabel }}(0,468<1,658)$ maka $\mathrm{H}_{\mathrm{o}}$ diterima yang berarti tidak terdapat pengaruh antara variabel Disiplin Kerja terhadap kinerja karyawan. Dilihat dari signifikansi 0,641>0,005 sehingga $\mathrm{H}_{\mathrm{o}}$ diterima.

- $t_{\text {hitung }}>\mathrm{t}_{\text {tabel }}(3,031>1,658)$ maka $\mathrm{H}_{\mathrm{o}}$ ditolak yang berarti terdapat pengaruh antara variabel Komunikasi Organisasi terhadap kinerja karyawan. Dilihat dari signifikansi $0,003<0,005$ sehingga $\mathrm{H}_{\mathrm{o}}$ ditolak.

\section{PEMBAHASAN}

\section{H1 : Pengaruh Pelatihan terhadap Kinerja}

Terdapat pengaruh antara variabel pelatihan terhadap kinerja karyawan berdasarkan $t_{\text {hitung }}>$ $t_{\text {tabel }}(2,140>1,658)$ dengan signifikansi $0,035<0,005$. Nilai t-hitung positif artinya hal ini membuktikan bahwa semakin baik pelatihan yang diberikan maka akan semakin baik kinerja karyawan

\section{H2 : Pengaruh Disiplin Kerja terhadap Kinerja}

Berdasarkan $t_{\text {hitung }}<t_{\text {tabel }}(0,468<1,658)$ dengan nilai signifikansi 0,641 $>0,005$ artinya Ho diterima maka disiplin kerja tidak terdapat pengaruh yang signifikan terhadap kinerja karyawan.

\section{H3 : Komunikasi Organisasi terhadap Kinerja}

Terdapat pengaruh antara variabel komunikasi organisasi terhadap kinerja. Berdasarkan $\mathrm{t}_{\text {hitung }}$ $<t_{\text {tabel }}(3,031>1,658)$ dengan nilai signifikansi $0,003<0,005$ artinya Ha diterima maka terdapat pengaruh variabel komunikasi organisasi terhadap kinerja karyawan.

\section{KESIMPULAN \& SARAN}

Berdasarkan hasil penelitian maka dapat ditarik beberapa kesimpulan :

1. (X1) berpengaruh secara signifikan terhadap (Y).

2. (X2) tidak berpengaruh dan tidak signifikan terhadap (Y).

3. (X3) berpengaruh secara signifikan terhadap (Y).

4. (X1), (X2) dan (X3) secara simultan berpengaruh secara signifikan terhadap (Y).

Saran:

1. Untuk pelatihan, perlunya instruktur yang berpengalaman dan mampu memotivasi.

2. Di dalam disiplin kerja, perusahaan perlu melakukan pengawasan dan evaluasi.

3. Perusahaan melakukan komunikasi bottom up dan forum group disscusion

4. Untuk peneliti lain dapat dicari variabel lain yang berpengaruh terhadap kinerja.

\section{DAFTAR PUSTAKA}

Agung Setiawan, (2013); Analisis pengaruh Disiplin Kerja dan Motivasi pada Kinerja karyawan RSUD Kanjuruhan Malang: Jurnal Ilmu Manajemen, FE Universitas Negeri Surabaya, Vol.1 Nomor 4 Juli 2013, https://www.academia.edu/28874845/ di akses : 2 Juli 2019

Ananta D.S. \& S.Kempa (2017) Pengaruh Kompensasi dan Disiplin Kerja terhadap Kinrja Kerywan PT. Modern Widya Technical Cabang Jaya Pura; Program Studi Manajemen Bisnis, Fakultas Ekonomi, Universitas Kristen Petra. Hal. 121-131, Jurnal. AGORA Vol. 5 ,

Desy Ernika (2016); Analisis Pengaruh antara komunikasi organisasi dan motivasi terhadap kinerja karyawan pada PT. Inti Tractors Samarinda, eJournal Ilmu Komunikasi, 2016 : 4 (2) : 87 - 101 ISSN 0000-0000, ejournal.ilkom.fisip-unmul.ac.id CCopyright 2016, http://ejournal.ilkom.fisipunmul.ac.id/site/wpcontent/uploads/2016/05/Jurnal\%20Desy \%20(05-13-16-01-06-37).pdf di asks : 2 Juli 2019

Devito, Joseph A.1997. Komunikasi antarmanusia (5th ed), Jakarta : Proffesionals Books 
Edi Saputra Pakpahan, Siswidiyanto, Sukanto, Pengaruh Pendidikan dan Pelatihan terhadap Kinerja pegawai Badan Kepegawaian Daerah Kota Malang), Jurnal Administrasi Publik (JAP) Jurusan Administrasi Publik, Fakultas Ilmu Administrasi, Universitas Brawijaya, Malang, Vol. 2, No. 1,Hal. 116-121 https://media.neliti.com/media/publications/77103ID-pengaruh-pendidikan-dan-pelatihan : diakss 1 April 2019

Fendy Levy Kambey, Suharnomo, 2013, Pengaruh Pembinaan, Pelatihan , Pemberdayaan dan Partisipasi terhadap Kinerja Karyawan, Jurnal Studi Manajemen \& Organisasi Vol 10, No 2, Juli Tahun. 2013, Halaman 142-151.II

Ghozali, Imam. (2016). Aplikasi Analisis Multivariete Dengan Program (IBM-SPSS). Edisi 8. Semarang: Badan Penerbit Universitas Diponegoro

Ike Kusdyah (2008), Manajemen Sumber Daya Manusia, Yogyakarta: Andi Offset

L. Paramita., V.P.K. Lengkong., G.M. Sendow. (2016); Pengaruh Komunikasi Organisasi \& stress Kerja terhadap Kepuasan Konsumen serta dampaknya terhadap Kinerja Karyawan di Perusahaan Bulog Divisi Regional Sulawesi Utara; Jurnal EMBA 131 Vol.4 No.1 Maret 2016; ISSN 2303-1174 akses : https://media.neliti.com/media/publications/2885ID di akses 1 Agustus 2019

M Sahangggamu, Petricia dan L. Mandey, Silvia. (2014). Pengaruh Pelatihan, Motivasi, dan Disiplin kerja terhadap kinerja karyawan (studi kasus di PT Bank Perkreditan Rakyat Dana Raya Manado). Jurnal EMBA. Vol.2, No.4, Desember.2014. Manado (ISSN 23031174). http://ejournal.unsrat.ac.id/index.php/emba/issue/view/610/showToc. Diakses 1 April 2019

Moeheriono. 2012. Perencanaan, Aplikasi, dan Pengembangan Indikator Kinerja Utama (IKU) Bisnis dan Publik. Jakarta : PT. RajaGrafindo Persada.

Priyatno Duwi. (2014). SPSS 22 Pengolahan Data Terpraktis. Yogyakarta

Robbins SP, dan Judge, (2002). Perilaku Organisasi. Buku 2, Jakarta: Salemba Empat Hal 260

S.Srimiatun,T.Prihatinta,(2017): Pengaruh Komunikasi Dan Konflik Terhadap Kinerja Karyawan Jurnal Manajemen Politekhnik Negeri Madiun; journal.pnm.ac.id Epicheirisi; Volume 1 Nomor 1 Tahun 2017

Schein, E. H. 2008. Organizational Culture and Leadership. San Francisco: Jossey-Bass

Sugiyono. 2012. Metode Penelitian Kuantitatif Kualitatif dan R \& D. Bandung: Alfabeta. 